Quanto à presença das bactérias invasoras, nos estudos do Rio prevaleceu a Salmonella, enquanto que nos demais trabalhos anteriores, e neste atual, a Shiguella foi a mais freqüente. Campylobacter, ECEH, Yersinia e ECEI são considerados a seguir, nessa ordem, em todo o mundo ${ }^{12,13}$.

Merece destaque neste trabalho da Dra Eloísa Souza e colaboradores o detalhado estudo da participação da E. coli na diarréia aguda em populações carentes do estado de São Paulo. Acredito ser isto fruto da influência do eminente cientista e professor Luiz Rachid Trabulsi, pioneiro nos estudos relativos à participação da ECEP na diarréia aguda em nosso meio, a quem rendo minhas homenagens, extensiva a todos que participaram desta excelente revisão etiopatogênica da diarréia aguda em São Paulo, sob a liderança do professor Yassuhiko Okay.

\section{Referências bibliográficas}

1. Sabrá A. Diarréia Aguda e Crônica em Pediatria. $4^{a}$ ed. Rio de Janeiro: Ed. Cultura Médica; 1994.p.93.

2. Souza EC, Martinez MB, Taddei CR, Mukai L, Gilio AE, Racz ML, et al. Perfil etiológico das diarréias agudas de crianças atendidas em São Paulo. J Pediatr (Rio J) 2002;78(1):31-38.
3. Wrong O, Metcaff-Gibson A. The electrolyte content of feces. Proc Roy Soc Med 1965; 58: 1007.

4. Kerzner B, Kelly M, Gall D, Butler D, Hamilton J. Transmissible gastroenteritis - sodium transport and the intestinal epithelium during the course of viral enteritis. Gastroenterology 1977; 72:457.

5. Sabrá A. Diarréia Aguda e Crônica em Pediatria. $4^{a}$ ed. Rio de Janeiro: Ed. Cultura Médica; 1994.p.110.

6. Sharp C, Hynie S. Stimulation of intestinal adenylyl cyclase by cholera toxin. Nature 1971; 229: 226.

7. Sabrá A. Diarréia Aguda e Crônica em Pediatria. $4^{a}$ ed. Rio de Janeiro: Ed. Cultura Médica; 1994.p. 97.

8. Guerrant RL, Hughes JM, Lima NL, Crane J. Diarrhea in developed and developing countries: magnitude, special setting, and etiologies. Rev Infect Dis 1990; 12(S):41.

9. Kitagawa SMS, Toledo MRF, Trabulsi LR, et al. Etiologia da diarréia infecciosa endêmica da criança de baixo nível sócioeconômico em São Paulo. Am J Trop Med Hyg 1986; 35:1013.

10. Sabrá A. Diarréia Aguda e Crônica em Pediatria. $4^{a}$ ed. Rio de Janeiro: Ed. Cultura Médica; 1994.p.104.

11. Silva LR. Diarréia aguda em crianças. $1^{a}$ ed. Rio de Janeiro: Ed. Medsi; 1988; 73.

12. Stumph M, Ricciardi ID, Oliveira N, Sabrá A, Bernhoeft M. Yersinia enterocolítica as a cause of infantile diarrhoea in Rio de Janeiro. Rev Bras Pesq Med Biol 1979; 11: 383.

13. Ricciardi ID, Ferreira MCS, Otto SS, Oliveira N, Sabrá A, Fontes CF. Thermophilic Campylobacter - Associated Diarrhea in Rio de Janeiro. Rev Bras Pesq Med Biol 1979; 12: 189.

\title{
Desnutrição e epilepsia
}

\author{
Malnutrition and epilepsy
}

\author{
Aristea S. Galanopoulou ${ }^{1}$, Solomon L. Moshé2
}

Crises convulsivas e epilepsia ocorrem em crianças com mais freqüência do que em qualquer outra faixa etária ${ }^{1}$. As causas das crises convulsivas variam desde crises convulsivas provocadas até crises convulsivas associadas a uma predisposição genética, ou mesmo crises convulsivas após lesões no cérebro em desenvolvimento. A desnutrição parece ser um grande problema em países em desenvolvimento, afetando principalmente as crianças. De forma similar às crises convulsivas, as lesões nutricionais que acontecem precocemente podem afetar profunda e permanentemente a maturação do sistema nervoso central. Em modelos animais, além de retardar o crescimento cerebral, a desnutrição pode também diminuir o dendrito apical e reduzir o número de espinhas dendríticas ${ }^{2}$. A relação entre a desnutrição e as crises convulsivas não tem sido adequadamente explorada. Há estudos que sugerem que as crian-

1. MD PhD, Depto. de Neurologia e Unidade Extensiva de Epilepsia/ Einstein - Faculdade de Medicina Albert Einstein, Bronx, NY, EUA.

2. MD, Deptos. de Neurologia, Pediatria, Neurociência e Unidade Extensiva de Epilepsia/ Einstein - Fac. de Medicina Albert Einstein, Bronx, NY, EUA. ças desnutridas possam estar mais propensas a crises convulsivas do que as bem nutridas ${ }^{3}$. Existem, ainda, vários estudos com animais que sugerem uma diminuição nos limiares para crise convulsiva em modelos de epilepsia ${ }^{4-6}$. Além disso, a desnutrição afeta a maturação dos padrões EEG em ratos, e a eficácia sináptica ${ }^{7}$. A desnutrição também pode influenciar as conseqüências de crises convulsivas, resultando em lesão exagerada induzida por crises convulsivas e em consequiências que podem produzir efeitos prejudiciais para toda a vida. Em um estudo anterior, Nunes et al. apresentaram dados sobre a possibilidade da desnutrição influenciar a neoneurogênese no hipocampo imaturo e intensificar a neoneurogênese grave induzida por estado epilético no giro denteado em ratos imaturos $^{6}$.

Há que se louvar a busca constante do grupo liderado pela Dra. Nunes, através de uma série de estudos, no sentido de determinar os efeitos da desnutrição no cérebro em desenvolvimento, identificar os mecanismos pelos quais a desnutrição pode influenciar os limiares para crise convul- 
siva, e definir se os déficits podem ser melhorados através de reabilitação ${ }^{8}$. Nesta edição do Jornal de Pediatria, os autores relatam suas descobertas a partir de um modelo de desnutrição que eles estabeleceram em seu laboratório, em Porto Alegre. Os dados indicam que eles desenvolveram uma maneira eficiente de produzir desnutrição em filhotes de ratos, e que são capazes de reverter o processo, pelo menos em relação às alterações no peso corporal, através da reabilitação nutricional. É interessante notar que, nesse modelo, os limiares para crises convulsivas induzidas por flurotil (um modelo para crises convulsivas primárias generalizadas) não são afetados pela desnutrição. Além disso, nessa condição de reabilitação precoce, a exposição prévia ao estado epilético não alterou a suscetibilidade dos ratos desnutridos a ataques subseqüentes. Isto contrasta com estudos anteriores que mostram que a desnutrição seguida pela reabilitação em ratos mais velhos diminui o limiar para crise convulsiva em uma variedade de modelos experimentais $5,7,9$. Os dados apresentados sugerem que os efeitos da desnutrição podem ser específicos em relação a certas áreas do cérebro, e que estudos mais aprofundados são necessários. Além disso, a reabilitação nutricional precoce pode reverter quaisquer efeitos prejudiciais em potencial que a combinação entre a desnutrição inicial e o estado epilético sobreposto possa ter causado.

Paradoxalmente, um outro tipo de "desnutrição", a dieta cetogênica, vem sendo utilizada com eficácia como uma modalidade anti-convulsivante em crianças. A eficácia da dieta cetogênica também foi documentada em vários modelos experimentais de convulsão ${ }^{10-12}$, e está freqüentemente associada a déficits no ganho de peso. Bough et al. relataram que a restrição de calorias per se confere maior resistência a crises convulsivas induzidas por pentilenotetra$\mathrm{zol}^{11}$. Nesses modelos, a proteção contra crises convulsivas dependeu amplamente da idade, da restrição de calorias ${ }^{11}$, do modelo da crise ${ }^{13}$, do tempo de iniciação ${ }^{14}$, e do conteúdo nutricional da dieta específica ${ }^{13}$. É possível que os mesmos fatores possam determinar os efeitos contrastantes da dieta cetogênica se comparada a dietas não-cetogênicas de desnutrição.

Esses dados fazem com que surjam outras questões. É bem possível que a desnutrição possa ser mais predominante em crianças com deficiência no desenvolvimento. Nesse caso, os efeitos da desnutrição no desenvolvimento cerebral posterior e nas crises convulsivas podem ser ainda mais profundos do que aqueles observados em crianças com cérebros normais. Estudos sobre os efeitos da desnutrição em roedores com desenvolvimento anormal podem servir para elucidar como a desnutrição influencia o desenvolvimento sob essas circunstâncias, e se a suscetibilidade à convulsão e suas consequiências são mais profundas nessas circunstâncias, se comparadas àquelas de indivíduos desnutridos, mas sem quaisquer anormalidades cerebrais. $\mathrm{Ou}-$ tros fatores complicadores podem incluir infecções concomitantes e exposição a toxinas ambientais. Com os recentes avanços na pesquisa médica, já é possível estudar esses efeitos combinados para desenvolver tratamentos racionais e eficientes, que incluam o papel possivelmente benéfico da exposição a ambientes enriquecidos. Obviamente, em primeiro lugar, não se deve medir esforços para erradicar a desnutrição.

\section{Referências bibliográficas}

1. Swann JW, Moshé SL. Developmental issues in animal models. In: Engel Jr. J, Pedley TA, eds. Epilepsy: a comprehensive Textbook. Philadelphia: Lippincott-Raven Publishers; 1997. p.467-79.

2. Benitez-Bribiesca L, De la Rosa-Alvarez I, Mansilla-Olivares A. Dendritic spine pathology in infants with severe protein-calorie malnutrition. Pediatrics 1999; 104(2):e21.

3. Nunes ML, Texeira CG, Fabris I, Goncalves RA. Evaluation of the nutritional status in institutionalized children and its relationship to the development of epilepsy. Nutritional Neuroscience 1999; 2:139-45.

4. Bronzino JD, Austin-Lafrance RJ, Siok CJ, Morgane PJ. Effect of protein malnutrition on hippocampal kindling: electrographic and behavioral measures. Brain Res 1986; 384(2):348-54.

5. Gietzen DW, Dixon KD, Truong BG, Jones AC, Barrett JA, Washburn DS. Indispensable amino acid deficiency and increased seizure susceptibility in rats. Am J Physiol 1996; 271(1 Pt 2):R18-24.

6. Nunes ML, Liptakova S, Veliskova J, Sperber EF, Moshe SL. Malnutrition increases dentate granule cell proliferation in immature rats after status epilepticus. Epilepsia 2000; 41(Suppl 6): S48-52.

7. Morgane PJ, Austin K, Siok CJ, LaFrance R, Bronzino JD. Power spectral analysis of hippocampal and cortical EEG activity following severe prenatal protein malnutrition in the rat. Brain Res 1985; 354 211-18.

8. Nunes ML, Batista BB, Micheli F, Batistella V. Effects of early malnutrition and nutritional rehabilitation in rats. J Pediatr (Rio J) 2002; 78(1):39-44.

9. Taber KH, Fuller GN, Stanley JC, DeFrance JF, Wiggins RC. The effect of postnatal undernourishment on epileptiform kindling of dorsal hippocampus. Experientia 1980; 36(1):69-70.

10. Hori A, Tandon P, Holmes GL, Stafstrom CE. Ketogenic diet: effects on expression of kindled seizures and behavior in adult rats. Epilepsia 1997; 38(7):750-8.

11. Bough KJ, Valiyil R, Han FT, Eagles DA. Seizure resistance is dependent upon age and calorie restriction in rats fed a ketogenic diet. Epilepsy Res 1999; 35(1):21-8.

12. Muller-Schwarze AB, Tandon P, Liu Z, Yang Y, Holmes GL, Stafstrom CE. Ketogenic diet reduces spontaneous seizures and mossy fiber sprouting in the kainic acid model. Neuroreport 1999; 10(7):1517-22.

13. Thavendiranathan P, Mendonca A, Dell C, Likhodii SS, Musa K, Iracleous $\mathrm{C}$, et al. The MCT ketogenic diet: effects on animal seizure models. Exp Neurol 2000; 161(2): 696-703.

14. Su SW, Cilio MR, Sogawa Y, Silveira DC, Holmes GL, Stafstrom $\mathrm{CE}$, et al. Timing of ketogenic diet initiation in an experimental epilepsy model. Brain Res Dev Brain Res 2000; 125(1-2):131-8.

Endereço para correspondência:

Solomon L. Moshé MD

Professor of Neurology, Neuroscience and Pediatrics

Albert Einstein College of Medicine

1410 Pelham Parkway South

Kennedy Center Rm 316

Bronx NY 10461 USA

E-mail:moshe@aecom.yu.edu

Tel: 718-430-2464 - Fax: 718-430-8899 